\title{
Osseointegration of standard and mini dental implants: a histomorphometric comparison
}

\author{
Jagjit S. Dhaliwall ${ }^{1 *}$, Rubens F. Albuquerque $\mathrm{Jr}^{2}$, Monzur Murshed ${ }^{1,3}$ and Jocelyne S. Feine ${ }^{1}$
}

\begin{abstract}
Background: Mini dental implants (MDIs) are becoming increasingly popular for rehabilitation of edentulous patients because of their several advantages. However, there is a lack of evidence on the osseointegration potential of the MDIs. The objective of the study was to histomorphometrically evaluate and compare bone apposition on the surface of MDls and standard implants in a rabbit model.

Methods: Nine New Zealand white rabbits were used for the study to meet statistical criteria for adequate power. Total $183 \mathrm{M}^{\mathrm{TM}} \mathrm{ESPE}^{\mathrm{TM}} \mathrm{MDIs}$ and 18 standard implants (Ankylos ${ }^{\circ}$ Friadent, Dentsply) were inserted randomly into the tibia of rabbits (four implants per rabbit); animals were sacrificed after a 6-week healing period. The specimens were retrieved en bloc and preserved in 10\% formaldehyde solution. Specimens were prepared for embedding in a light cure acrylic resin (Technovit 9100). The most central sagittal histological sections (30-40 $\mu \mathrm{m}$ thick) were obtained using a Leica SP 1600 saw microtome. After staining, the Leica DM2000 microscope was used, the images were captured using Olympus DP72 camera and associated software. Bone implant contact (BIC) was measured using Infinity Analyze software.
\end{abstract}

Results: All implants were osseointegrated. Histologic measures show mineralized bone matrix in intimate contact with the implant surface in both groups. The median BIC was $58.5 \%$ (IQR 8.0) in the MDI group and $57.0 \%$ (IQR 5.5) in the control group ( $P>0.05$; Mann-Whitney test). There were no statistical differences in osseointegration at 6 weeks between MDIs and standard implants in rabbit tibias.

Conclusions: Based on these results, it is concluded that osseointegration of MDIs is similar to that of standard implants.

Keywords: Bone implant contact, Mini dental implant, Osseointegration

\section{Background}

The term "osseointegration" was first introduced to explain the phenomenon for stable fixation of titanium to bone by Brånemark et al. in the 1960s [1]. Osseointegrated implants were introduced, a new era in oral rehabilitation began, and many studies were conducted $[2,3]$. A success rate of over $90 \%$ has been reported $[4,5]$. Further, a success rate of $81 \%$ in the maxillary bone and $91 \%$ in the mandible can be accomplished [6]. Dental implants have been widely used for the stabilization of

\footnotetext{
* Correspondence: jagjitd2002@yahoo.com

${ }^{1}$ Faculty of Dentistry, McGill University, 2001 McGill College Avenue, Suite

500, Montreal, Quebec H3A 1G1, Canada

Full list of author information is available at the end of the article
}

complete dentures and also help to maintain bone, function, esthetics, and phonetics and improve the oral healthrelated quality of life [7]. The dental implants are available with different surfaces and sizes. The size of the dental implants usually ranges in the diameter range of $3 \mathrm{~mm}$ (narrow diameter) to $7 \mathrm{~mm}$ (wide diameter). However, majority of the implants fall in the "standard diameter" range of 3.7 to $4.0 \mathrm{~mm}$ [8].

Mini dental implants or small size implants are also being widely used for stabilizing the complete dentures [9], for orthodontic anchorage [10-12], single tooth replacements [13, 14], fixing the surgical guides for definitive implant placement [15], and as transitional 
implants for the support of interim removable prosthesis during the healing phase of final fixtures [16, 17].

The single-piece mini dental implants (MDIs) are becoming increasingly popular for the purpose of denture stabilization. There are many advantages of the MDIs over the regular implants. The surgery is minimally invasive as compared with conventional implant surgery which helps in decreased morbidity for the patient. Transmucosal placement is possible using a single pilot drill, and these can often be loaded immediately [18]. Gingival healing is typically seen in 2 to 5 days, extended healing period with MDIs is usually not necessary [19]. The insertion of MDIs needs a minimal disturbance of the periosteum, thus osseointegration process is accelerated and time needed for MDIs tends to be considerably small than that of regular implants due to less injurious insertion procedure [9]. The need for sutures or long recovery periods is eliminated [3]. The patient can walk in to the office in the morning and is out the same day with a full set of teeth, the patient is allowed to eat the same day. These can work well for patients who have significant bone loss that restrict them from being a candidate for regular dental implants. MDIs are also a solution for patients that cannot have surgery for medical reasons. MDIs are also cost effective [20]. Considerable confusion exists in the literature regarding the best method to monitor the status of a dental implant. Various methods have been used to demonstrate the osseointegration of dental implants. A common and time-tested method to evaluate biological responses to an implant is to measure the extent of bone implant contact (BIC), referred to as histomorphometry at the light microscopic level. Bone implant contact (BIC) is one of the parameters which has been used extensively to study the amount of bone apposition next to the implants [21-27]. When an implant is placed in the jaw, it is in contact with compact bone as well as cancellous bone. The different structures of the two types of bone frequently result in variation of mineralized bone-to-implant contact length along the implant surface $[28,29]$. Albrektsson et al. identified the key features affecting osseointegration about 4 decades ago, e.g., implant surface and topography, surface chemistry, charge, and wettability [30]. Roughness and enhanced surface area seems to be helpful for osseointegration. Carlsson et al. reported that screw-shaped implants with a rough surface had a stronger bonding than implants with a polished surface [31]. A coarse surface seems to be more appropriate for osseointegration of implants than a relatively smoother implant surface by representing a greater degree of implant integration [32-34]. The bone contact areas of $3 \mathrm{M}^{\prime \prime \prime} E S P E E^{\prime \prime \prime}$ MDIs are surface treated. The treatment process of these MDIs includes sandblasting with aluminum oxide particles followed by cleaning and passivation with an oxidizing acid [35].
Despite the advantages of the mini dental implants, evidence on their efficacy and long-term success is lacking. The success of these implants will depend on their union with the surrounding bone. New implant systems entering into the market have to be studied with the help of animal models first, to demonstrate the osseointegration potential for their probable success in humans. There is a limited evidence regarding the $3 \mathrm{M}^{\text {"m }} \mathrm{ESPE}$ MDIs. Therefore, there is a need for an animal study to explore the osseointegration of these implants to assist in better understanding of the treatment selection, prognosis, and outcomes for the patients.

\section{Objectives of the study}

The objective of this study is to compare bone apposition on the surface of mini dental implants and standard implants by means of histomorphometric methods.

\section{Methods}

Animal model

Nine clinically healthy New Zealand white rabbits weighing $3.5 \mathrm{~kg}$ and more were used for the study, and the animals were housed in the central animal house facility. The head of tibia/femur of the animals were used for the implantation of samples. Rabbits' tibiae and femur have been widely used as an animal model by various other authors to study osseointegration of dental implants [36-45].

\section{Sample size}

The sample size of this study has been calculated based on the results of a similar study by Bornstein et al. [22]. It was established that $88 \%$ statistical power will be achieved by using 18 mini dental implants ( $3 \mathrm{M}^{\mathrm{m}} \mathrm{ESPE}^{\mathrm{m}}$ MDIs) for the experimental implants and equal number of an established regular implant (Ankylos;, Dentsply Friadent $\mathrm{GmbH}$ ) for the control. Therefore, the total number of implants used was 36. Each animal received four implants on hind limbs, i.e., right and left tibia/ femur head randomly (the heads of tibia and femur have been chosen to get the maximum bulk of bone). Therefore, each animal received two experimental and two regular implants.

\section{Surgical procedure}

The procedures were approved by the institutional animals' ethics review board of McGill University, Canada. Animals were anesthetized by an intravenous injection of ketamine hydrochloride-xylazine mixture at 35-50 and $1-3 \mathrm{mg} / \mathrm{kg}$ respectively according to a method described by Green et al. [46]. Acepromazine was injected subcutaneously at dosage of $1 \mathrm{mg} / \mathrm{kg}$. Further injections of the mixture were given to maintain anesthesia, if necessary [46]. Sterile ophthalmic ointment was put in 
both eyes to prevent corneal desiccation. Animals were shaved for twice the size of the expected surgical field with an electric razor. All loose hair and debris from the animal were removed. The surgical area was cleaned with gauze and $2 \%$ chlorhexidine solution to remove the majority of debris from the surgical site. Antiseptic skin preparation was done starting at the center of the surgical site and moved to the outside of the prepared area in a circular manner. Three scrubs with $2 \%$ chlorhexidine solution and three alternating rinses with alcohol were performed. The animal was draped and fixed with clamps on a sterile, impermeable covering to isolate the disinfected area. This was performed by the gloved and gowned surgical team under sterile conditions.

\section{Surgical protocol for $3 \mathrm{M}^{\mathrm{Tm}} \mathrm{ESPE}{ }^{\mathrm{Tm}} \mathrm{MDIs}$}

A small longitudinal skin incision just distal to the tibiafemur joint was made. The tibia/femur head was exposed subperiosteally and an osteotomy performed with the delicately placed pilot drill over the entry point and lightly pumped up and down under copius saline irrigation just to enter the cortical bone for the MDIs. This was used for initial bone drilling to depth of $0.5 \mathrm{~mm}$. The $3 \mathrm{M}^{\mathrm{m}}{ }^{\mathrm{E}} \mathrm{ESPE} \mathrm{m}^{\mathrm{m}}$ MDI (size $1.8 \mathrm{~mm} \times 10 \mathrm{~mm}$ ) vial was opened and the body of the implant was firmly grasped with a sterilized locking pliers. The titanium finger driver was attached to the head of the implant. The implant was transferred to the site and rotated clockwise while exerting downwards pressure. This began the self tapping process and was used until noticeable bony resistance encountered when it touched the lower cortical plate. The winged thumb wrench was used for driving the implant deeper into the bone, if necessary. All the animals received one MDI on the head of each tibia or femur. Therefore, total 18 mini dental implants were inserted.

\section{Surgical protocol for the Ankylos implants}

Equal number of comparator implants (size $3.5 \mathrm{~mm} \times$ $8 \mathrm{~mm}$ ) were inserted in the other tibia/femur head of the animals after doing the osteotomy according to the manufacturer's protocol as follows. After mobilizing the mucoperiosteal flap, the 3-mm center punch was used to register a guide for the twist drill. The twist drill was used to establish the axial alignment of the implant and to assist in the guidance of the depth drill. The depth drills were sequentially used to create osteotomy to the subcrestal axial depth of $0.5 \mathrm{~mm}$. The conical reamer was used to develop the conical shape of the implant body and to check the osteotomy depth. A counterclockwise rotation was used to compress the bone in soft bone. The tap or thread cutter was used for dense bone to create the threads in the osteotomy. The thread cutter's diameter corresponds to the implant diameter.
To engage the implant into the implant placement tool, the square faces on the implant fixture mount were aligned with those on the implant placement tool, then pushed together. Using the handle (finger wheel), the implant was pulled out of inner vial and the plastic collar was discarded. The implant placement assembly was transferred to the osteotomy and the implant was secured into the osteotomy site. The implant placement was started with the handle and finally placed using the hand-ratchet. If excessive force was experienced, the osteotomy was rinsed out and the depth was checked by retapping. To disengage fixture mount from implant, the open-ended spanner was used to break the retention force of the fixture mount retention screw. The knurled top of the implant placement tool was turned by hand to fully disengage the fixture mount with the implant. Pushing down on the knurled top of the implant placement tool disengaged the fixture mount.

\section{Suturing}

Expected length of the procedure was approximately $1 \mathrm{~h}$. Following placement of the implants, the wound was sutured in layers. The underlying muscle, fascia, and dermal layers were sutured with the help of Vicryl (Polyglactin 910) suture with $3 / 8$ circle reverse cutting needle. The skin was sutured to a primary closer with the same suture material.

\section{Radiograph}

Plain X-ray images of all the rabbit tibia were taken after suturing to confirm the position of implants and to detect any injury/fracture of the bone (Fig. 1).

\section{Post surgical treatment}

After the surgical procedure, the animals were housed in a cage under the supervision of a veterinary doctor until they came out of anesthesia. The rabbit was observed every $2 \mathrm{~h}$ on the first day of surgery followed by once a day to check the wound for infection. The wound was protected with povidone iodine ointment. The rabbits were allowed immediate weight bearing as tolerated; therefore, they had no restraints on weight bearing.

Animals were shifted and housed together with other rabbits. The rabbit was given a dose of Cephalexin $12 \mathrm{mg} / \mathrm{kg} 0.5 \mathrm{ml} \mathrm{I.V}$. once intraoperatively and a postoperative analgesic, i.e., Carprofen $2-4 \mathrm{mg} / \mathrm{kg}$ S.C. every 8 hourly for 3 days according to McGill SOP. The routine daily care was as per McGill SOP\#524.01.

The feeding protocols were followed according to the university central animal house facility guidelines. The animals had a free access to water and feed. The sutures were removed after 7-10 days, and the wound was cleaned with $0.2 \%$ chlorhexidine solution. 


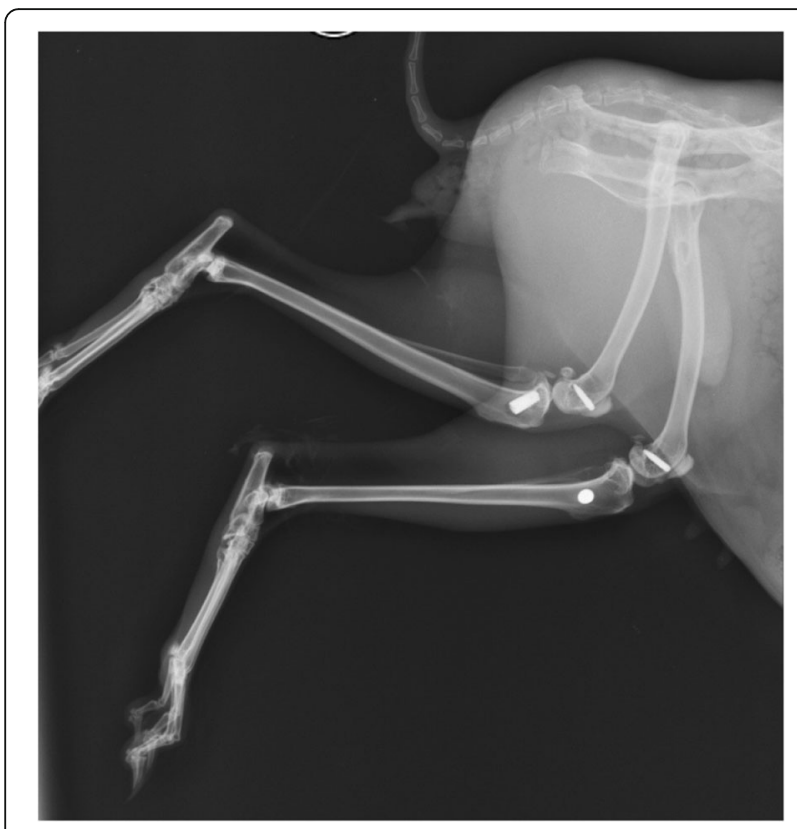

Fig. 1 Radiograph showing implants in the rabbit tibia

\section{Euthanasia}

The animals were euthanized at 6 weeks respectively. An overdose of pentobarbital sodium $1 \mathrm{ml} / \mathrm{kg}$ intravenously, under general anesthesia, was used for this purpose [47, 48].

\section{Specimen retrieval}

The implants along with their surrounding bone were excised with a surgical saw right away following the euthanasia. The excess tissue was dissected and the specimens were removed en bloc with a margin of surrounding bone of about 5-10 $\mathrm{mm}$. The specimens were immediately put into the $10 \%$ formaldehyde solution.

\section{Sample preparation for embedding}

The specimens were dehydrated in the ascending graded ethanol solution and kept in a pre-filtration solution for $3 \mathrm{~h}$ at room temperature and then in the filtration solution at $4{ }^{\circ} \mathrm{C}$ for $17 \mathrm{~h}$. The specimens were then embedded in a light curing resin Technovit 9100 NEW (Kulzer \& Co., Wehrheim, Germany) polymerization system based on methyl methacrylate, specially developed for embedding mineralized tissues for light microscopy. The polymerization mixture was produced by mixing the solution $\mathrm{A}$ and $\mathrm{B}$ in the proportion of 9 parts $\mathrm{A}$ and 1 part of solution B directly before use. This was done in a beaker and using a glass rod to stir the mixture. The samples were then positioned in the labeled plastic moulds, completely covered in the polymerization mixture, and placed in cooled desiccators and under a partial vacuum at $4{ }^{\circ} \mathrm{C}$ for $10 \mathrm{~min}$. The resulting blocks were placed in a sealed container and left to polymerize between -8 and $-20{ }^{\circ} \mathrm{C}$. The samples were allowed to stand at $4-8{ }^{\circ} \mathrm{C}$ in the refrigerator for at least $1 \mathrm{~h}$ before allowing it to slowly come to room temperature. The polymerization times are dependent on the volumes of polymerization mixture used and of the constancy of the temperature at which polymerization is carried out.

\section{Preparation of histological sections}

The acrylic block was mounted into the object holder of the Leica SP 1600 saw microtome (Fig. 2). The height of the object was adjusted until the surface of the object is slightly above the upper edge of the saw blade. The surface of the block was trimmed to get a plane surface prior to producing slices of a defined thickness. During the sawing process, the water flow was adjusted so that the water jet lands on the edge of the saw blade. The built-in water cooling device prevents overheating of the object and removes saw dust from the cutting edge and thus prolongs the lift time of the saw blade. The most favorable feed rate was determined (Fig. 3). After trimming, the first undefined slice was removed from the saw blade. The desired section thickness was selected, considering the thickness of the saw blade and added to the desired thickness of final section. The section was stabilized during the sawing process. To do so, a glass cover slip was glued onto the trimmed surface of the specimen block using cyanoacrylate glue. These blocks were cut with a low speed saw under water along the lateral surface of the implant $[47,48]$. The implant

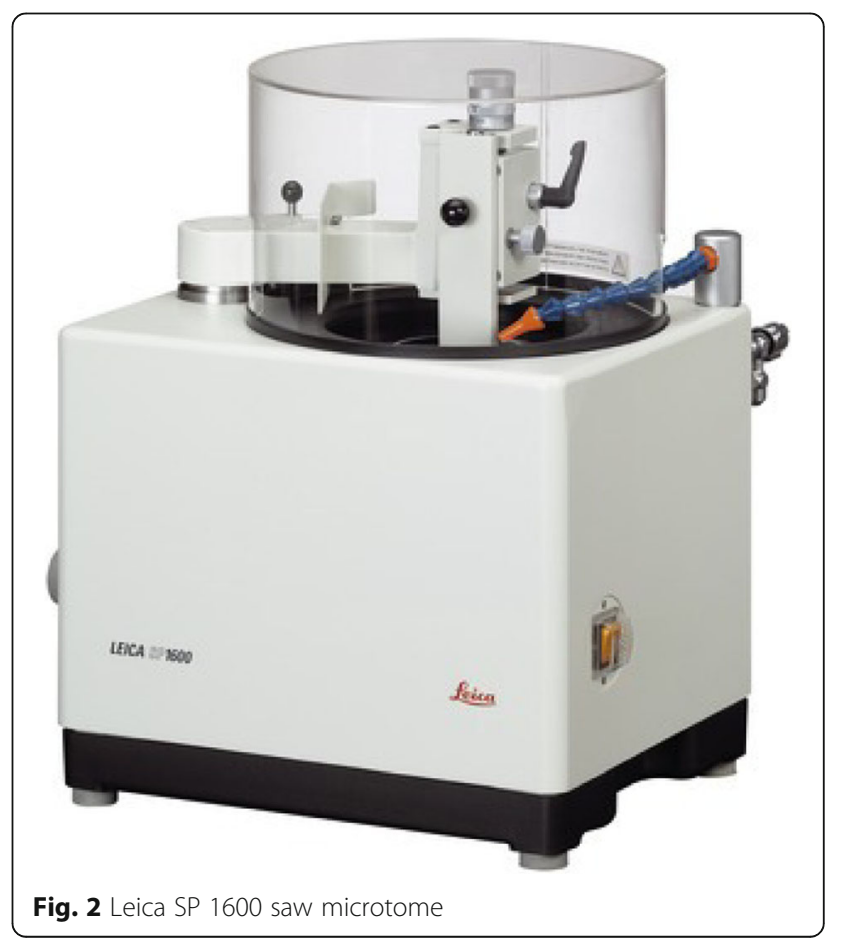




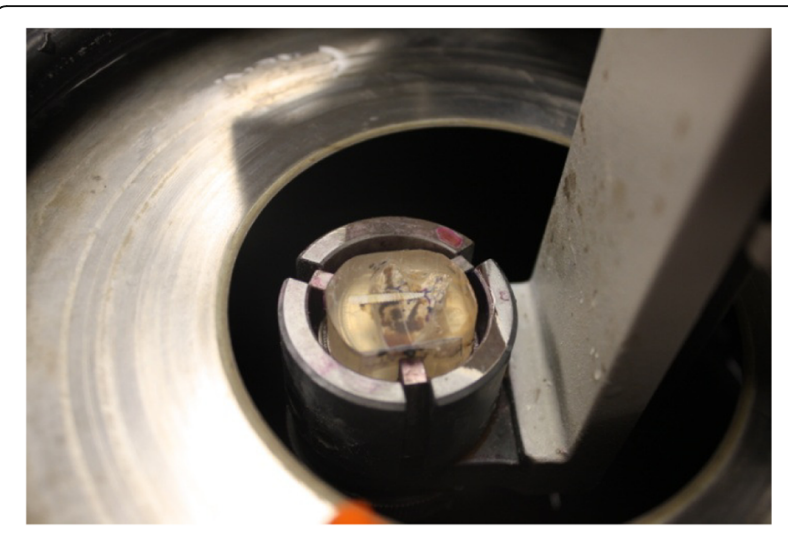

Fig. 3 Histological sections being obtained with Leica SP 1600 saw microtome

bearing blocks were cut parallel to the long axis of the implant, and $30-\mu \mathrm{m}$-thick specimens were obtained.

The saw blade has a thickness of $280 \mu \mathrm{m}$ and a feed of $310 \mu \mathrm{m}$ was selected to obtain the final section thickness of $30 \mu \mathrm{m}$. The knurled screw was used for the setting of the section thickness. The prepared section was finally removed from the saw blade. The specimens were prepared for histology by the method as described by Donath and Breuner [49].

\section{Histological evaluation}

Subsequently, the sections were stained with toluidine blue and basic fuchsin similar to other studies [21, 22, 50]. The specimen sections were evaluated at the most central saggital section of each implant under an optical microscope after staining. The images were photographed with a high resolution camera and interfaced to a monitor and PC, observed under the Leica DM2000 microscope, and the images were captured using Olympus DP72 camera and associated software [4, 21, 22]. Bone implant contact (BIC) was measured using Infinity Analyze software. Six images of the same implant were taken and measurements were done. The percentage of the interface contact length between implant surface and bone, i.e., bone implant contact (BIC), was calculated. The percentage of bone tissue in a $200-\mu \mathrm{m}$-wide zone parallel to the contour of the implant area (adjoining the implant) was measured.

\section{Micro-computed tomography (MicroCT)}

MicroCT scans of each sample of both types of implants were obtained with a Skyscan 1172 equipment (Kontich, Belgium) at $6 \mu \mathrm{m}$ resolution with $800 \mathrm{~ms}$ exposure time, $70 \mathrm{kV}$ electric voltage, $167 \mu \mathrm{A}$ current, and a $0.5-\mathrm{mm}$ thickness aluminum filter. The equipment was fitted with a 1.3-MP camera to capture high resolution 2D images that were assembled into 3D reconstructions using NRecon software supplied with the instrument.

\section{Statistical methods}

Mean values and standard deviations were calculated for bone implant contact (BIC). Univariate analysis was done for all the evaluations. Analysis of variance (ANOVA) was used to analyze the differences between the two implants. $P$ value $<0.05$ was considered significant. Statistical analyses were carried out with the help of SPSS statistical software version 18 .

\section{Results}

\section{Clinical findings}

On the whole, postoperative wound healing in all the rabbits was good. None of them exhibited any signs of wound infection or exposure. A total of 36 specimens were retrieved for histological examination.

\section{Histological observations}

All of the implants in both groups showed osseointegration and displayed a good amount of bone contact length (Figs. 4 and 5). No discernible differences were noticed between both the groups. The zone of interest was $200 \mu \mathrm{m}$ in the peri-implant area of the implants on both sides. Due to large marrow spaces in the rabbit bone,

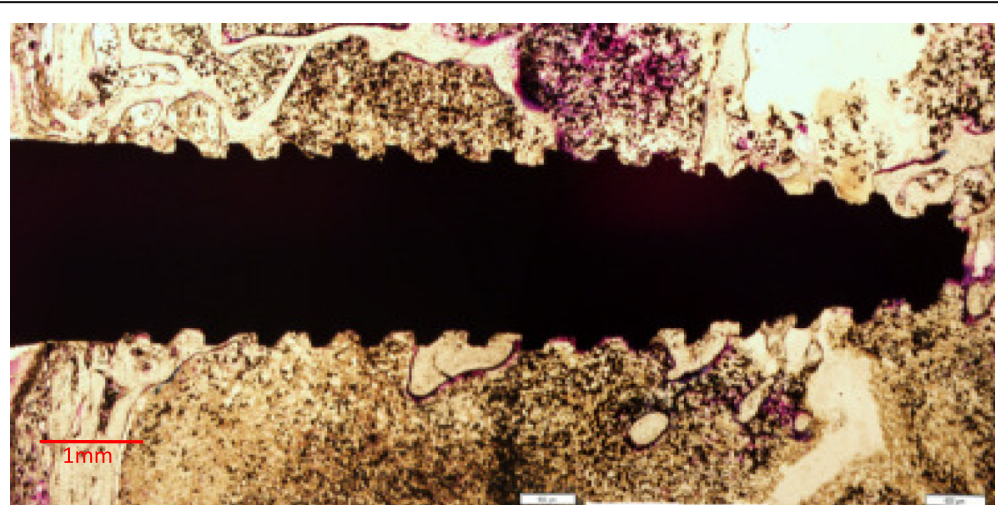

Fig. 4 Histological section of mini dental implant in rabbit tibia stained with methylene blue and basic fuchsin 


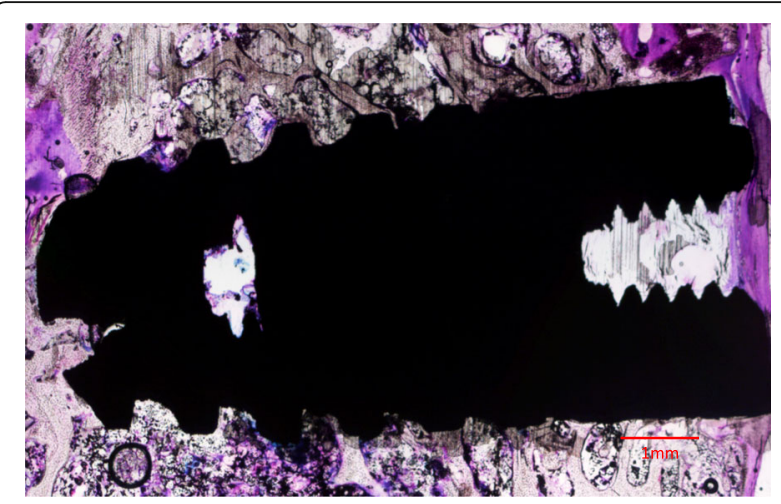

Fig. 5 Histological section of standard implant in rabbit tibia stained with methylene blue and basic fuchsin

larger volume of bone contact was mostly observed in the coronal and apical portions of the implants. The MicroCT pictures showed a three-dimensional deposition of bone in both samples (Fig. 6). It was noted that possibility of new bone formation was higher in areas adjacent to old bone. The sections of implant, which were exposed to the marrow spaces, displayed either no bone deposition or very thin bone tissue. Newly formed bone was seen with lighter staining. In the surrounding areas of both types of implants, bone fragments were noticed around the implant. These could correspond to bone fragments during the osteotomy procedure. Percentage of BIC ranged from 45 to $67 \%$ in both the groups. The median value of $\%$ BIC was 58.5 and the MDI group (IQR 7) and control group was 57.0 (IQR 5.0) (Tables 1 and 2). The mean differences of \% BIC between the groups were verified through Mann-Whitney nonparametric test. There was no significant difference between the $\%$ bone implant contact (BIC) length of both the implants $(P$ value $>0.05)$.

\section{Discussion}

The osseointegration potential of $3 \mathrm{M}^{\mathrm{m}} \mathrm{ESPE}$ MDIs has not been studied. The MDI is a one-piece implant that simplifies the restorative phase resulting in a reduced cost for the patient. Titanium-aluminum-vanadium alloy (Ti 6Al-4V-ELI) is used for increased strength. The success of these implants led to its use in long-term fixed and removable dental prostheses [51]. Conventional implant treatment requires adequate bone width and interdental space. Augmentation procedures are complex and can cause postoperative pain and discomfort for the patient and additional costs.

In human models, a 3-6-month period is needed to obtain osseointegration and animal models would need a shorter time (4-6 weeks) [30,33]. Rabbit has been used extensively to examine osseointegration and appears to be an appropriate model for studying the bone healing systems [52]. The healing periods used by various authors for assessing the bone implant contact in rabbits are $2,3,4,6,8$, and 12 weeks [53-57]. However, the best results have been between 6 and 12 weeks of insertion period $[51,53-55]$. The 6 -week healing period was carefully chosen after literature search. This was in agreement with others who have reported that a 6-week period is adequate in rabbits to develop a "rigid osseous interface" [51-60].

At the bone implant interface, woven bone starts forming after the placement of implant. Lamellar bone slowly replaces this scantily organized bone. The fully developed lamellar bone which replaces the woven bone typifies a stable and lasting osseointegration [61].

Our results are in concurrence with Balkin et al. [62]; they have also shown in their histology study in humans that the MDI undergoes osseointegration. They inserted one $3 \mathrm{M}^{\mathrm{m}} \mathrm{ESPE}^{\mathrm{mw}} \mathrm{MDI}$ of $1.8-\mathrm{mm}$ diameter in each of two patients as a transitional implant for mandibular dentures. After a period of 4 and 5 months, the implants were trephined out for histological evaluation. The results showed that there was a close apposition of bone on the implant surfaces. The bone surrounding the implant demonstrated signs of matured healing and integrated for immediate function after 4 to 5 months of healing period.

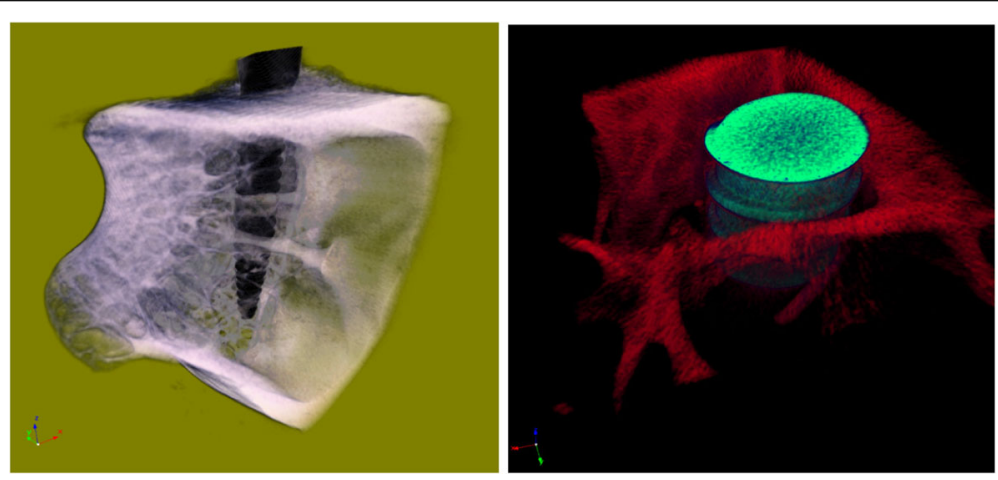

Fig. 6 Micro CT scan images of the MDIs and Ankylos embedded in rabbit bone 6 weeks post implantation 
Table 1 Comparison of \% BIC in both groups

\begin{tabular}{|c|c|c|}
\hline Sample & $3 \mathrm{M}^{\mathrm{m} m} \mathrm{ESPE}^{\mathrm{m} / \mathrm{M}} \mathrm{MD}$ & Ankylos \\
\hline 1. & 67 & 54 \\
\hline 2. & 59 & 67 \\
\hline 3. & 54 & 45 \\
\hline 4. & 51 & 58 \\
\hline 5. & 47 & 57 \\
\hline 6. & 64 & 49 \\
\hline 7. & 50 & 54 \\
\hline 8. & 60 & 56 \\
\hline 9. & 56 & 60 \\
\hline 10. & 61 & 53 \\
\hline 11. & 62 & 59 \\
\hline 12. & 61 & 55 \\
\hline 13. & 59 & 59 \\
\hline 14. & 45 & 51 \\
\hline 15. & 58 & 59 \\
\hline 16. & 54 & 62 \\
\hline 17. & 66 & 62 \\
\hline 18. & 56 & 57 \\
\hline
\end{tabular}

Our study is also in concordance with the results of a removal torque study by Simon et al. [63] in immediately loaded "transitional endosseous implants" in humans. The percentage BIC for MDIs was similar to standard implants.

The surface topography also affects the BIC, Wennerberg et al. [32] measured and compared removal torque values on screw-shaped titanium implants with three surface types. The results showed that screws sandblasted with $25-\mu \mathrm{m}$ particles of titanium and $75-\mu \mathrm{m}$ particles of aluminum oxide exhibited a higher removal torque and interfacial bone contact than the machined titanium implants with smoother surface texture.

The surface of $3 \mathrm{M}^{\mathrm{m}} \mathrm{ESPE}$ MDI is sandblasted with aluminum oxide and cleaned and passivized with an oxidizing acid (Technical Data Sheet, 3M ESPE) [35]. The surface of Ankylos is sandblasted and acid etched [64]. Various authors have reported that surface roughness induces a variety of events in the course of osteoblast differentiation, spreading and proliferation, production

Table 2 Descriptive statistics of the experimental and control group

\begin{tabular}{lll}
\hline BIC & $3 \mathrm{M}^{\mathrm{TM}} \mathrm{ESPE}^{\mathrm{TM}}$ MDIs & Ankylos $^{\circ}$ Friadent (Dentsply) \\
\hline Median & 58.5 & 57 \\
Mean & 57 & 56.5 \\
Interquartile range & 8 & 5.5 \\
First quartile & 53.25 & 53.75 \\
Third quartile & 61.25 & 59.25 \\
\hline
\end{tabular}

of alkaline phosphatase, collagen, proteoglycans, and osteocalcin, and synthesis of cytokines and growth factors [65-67]. Therefore, leading to bone deposition on the surface of these implants, Yan et al. [68] demonstrated that simple surface treatments can turn the titanium surface into a bone-bonding one. With the results of our in vitro study, Marulanda et al. [69] on discs of both types of implants demonstrated that surface chemistry of $3 \mathrm{M}^{\mathrm{m}} \mathrm{ESPE} \mathrm{E}^{\mathrm{m}} \mathrm{MDI}$ is conducive to growth of osteoblasts leading to bone apposition.

One of the shortcomings of our study may be the use of rabbit tibia as a model. The tibia of the rabbit is essentially hollow except the upper and lower cortical plates. This may justify lack of bone apposition on the whole implant in both experimental as well as comparator implants. However, it provides a reliable information for human application as the human maxillary bone is also of a softer bone quality [36, 51].

\section{Conclusions}

The results of this study show that MDIs as well as regular implants osseointegrate in rabbits.

\section{Funding}

This study was funded by Ministère du Développment économique de I'Innovation et ce I'Exportation (MDEIE), Gouvernement du Québec, Indian Council of Medical Research (ICMR) and 3M ESPE IRB grant number A10-M118-9A.

\section{Authors' contributions}

JSD carried out the experiments and drafted the manuscript, RA conceived the study and helped in revising the manuscript, MM contributed to the histological preparation and data analysis, JSF participated in this study's design and overall coordination. All authors read and approved the final manuscript.

\section{Competing interests}

Jagjit Singh Dhaliwal, Rubens F. Albuquerque Jr, Monzur Murshed and Jocelyne S. Feine declare that they have no competing interests.

\section{Ethical approval}

McGill University Research Ethics Board, Animal Use Protocol \# 2012-7221. All study procedures were conducted as per McGill SOPs. All efforts were made to minimize distress in animals throughout the experiments, as well as to use only the number of animals that was essential to produce reliable scientific data.

\section{Publisher's Note}

Springer Nature remains neutral with regard to jurisdictional claims in published maps and institutional affiliations.

\section{Author details \\ ${ }^{1}$ Faculty of Dentistry, McGill University, 2001 McGill College Avenue, Suite 500, Montreal, Quebec H3A 1G1, Canada. ${ }^{2}$ Faculty of Dentistry of Ribeirão Preto, University of São Paulo, Ribeirão Preto, SP, Brazil. ${ }^{3}$ Department of Medicine, McGill University, Montreal, Quebec, Canada.}

Received: 22 February 2017 Accepted: 26 April 2017

Published online: 01 May 2017

\section{References}

1. Branemark PI, Adell R, Breine U, Hansson BO, Lindstrom J, Ohlsson A. Intra-osseous anchorage of dental prostheses. I. Experimental studies. Scand J Plast Reconstr Surg. 1969;3(2):81-100. 
2. Boerrigter EM, Stegenga B, Raghoebar GM, Boering G. Patient satisfaction and chewing ability with implant-retained mandibular overdentures: a comparison with new complete dentures with or without preprosthetic surgery. J Oral Maxillofac Surg. 1995:53(10):1167-73.

3. Del Fabbro M, Testori T, Francetti L, Taschieri S, Weinstein R. Systematic review of survival rates for immediately loaded dental implants. Int J Periodontics Restorative Dent. 2006;26(3):249-63.

4. Buser D, Mericske-Stern R, Bernard JP, Behneke A, Behneke N, Hirt HP, et al. Long-term evaluation of non-submerged ITI implants. Part 1: 8-year life table analysis of a prospective multi-center study with 2359 implants. Clin Oral Implants Res. 1997;8(3):161-72.

5. Albrektsson T, Dahl E, Enbom L, Engevall S, Engquist B, Eriksson AR, et al. Osseointegrated oral implants. A Swedish multicenter study of 8139 consecutively inserted Nobelpharma implants. J Periodontol. 1988:59(5):287-96.

6. Adell R, Lekholm U, Rockler B, Branemark PI. A 15-year study of osseointegrated implants in the treatment of the edentulous jaw. Int J Oral Surg. 1981;10(6):387-416.

7. Heydecke G, Locker D, Awad MA, Lund JP, Feine JS. Oral and general health-related quality of life with conventional and implant dentures. Community Dent Oral Epidemiol. 2003;31(3):161-8.

8. Lee JH, Frias V, Lee KW, Wright RF. Effect of implant size and shape on implant success rates: a literature review. J Prosthet Dent. 2005;94(4):377-81.

9. Bulard RA, Vance JB. Multi-clinic evaluation using mini-dental implants for long-term denture stabilization: a preliminary biometric evaluation. Compend Contin Educ Dent. 2005;26(12):892-7.

10. Buchter A, Wiechmann D, Koerdt S, Wiesmann HP, Piffko J, Meyer U. Load-related implant reaction of mini-implants used for orthodontic anchorage. Clin Oral Implants Res. 2005;16(4):473-9.

11. Fritz $U$, Diedrich $P$, Kinzinger $G$, Al-Said $M$. The anchorage quality of mini-implants towards translatory and extrusive forces. J Orofac Orthop. 2003;64(4):293-304.

12. Hong RK, Heo JM, Ha YK. Lever-arm and mini-implant system for anterior torque control during retraction in lingual orthodontic treatment. Angle Orthod. 2005;75(1):129-41.

13. Mazor Z, Steigmann M, Leshem R, Peleg M. Mini-implants to reconstruct missing teeth in severe ridge deficiency and small interdental space: a 5-year case series. Implant Dent. 2004;13(4):336-41.

14. Siddiqui AA, Sosovicka M, Goetz M. Use of mini implants for replacement and immediate loading of 2 single-tooth restorations: a clinical case report. J Oral Implantol. 2006;32(2):82-6.

15. Yeh $\mathrm{S}$, Monaco EA, Buhite RJ. Using transitional implants as fixation screws to stabilize a surgical template for accurate implant placement: a clinical report. J Prosthet Dent. 2005;93(6):509-13.

16. Kwon KR, Sachdeo A, Weber HP. Achieving immediate function with provisional prostheses after implant placement: a clinical report. J Prosthet Dent. 2005;93(6):514-7.

17. Ohkubo C, Kobayashi M, Suzuki Y, Sato J, Hosoi T, Kurtz KS. Evaluation of transitional implant stabilized overdentures: a case series report. J Oral Rehabil. 2006;33(6):416-22.

18. Shatkin TE, Oppenheimer BD, Oppenheimer AJ. Mini dental implants for long-term fixed and removable prosthetics: a retrospective analysis of 2514 implants placed over a five-year period. Compend Contin Educ Dent. 2007; 28(2):92-9. quiz 100-1.

19. Campelo LD, Camara JR. Flapless implant surgery: a 10-year clinical retrospective analysis. Int J Oral Maxillofac Implants. 2002;17(2):271-6.

20. Griffitts TM, Collins CP, Collins PC. Mini dental implants: an adjunct for retention, stability, and comfort for the edentulous patient. Oral Surg Oral Med Oral Pathol Oral Radiol Endod. 2005;100(5):81-4.

21. Barros RR, Novaes Jr AB, Muglia VA, lezzi G, Piattelli A. Influence of interimplant distances and placement depth on peri-implant bone remodeling of adjacent and immediately loaded Morse cone connection implants: a histomorphometric study in dogs. Clin Oral Implants Res. 2010;21(4):371-8.

22. Bornstein MM, Valderrama P, Jones AA, Wilson TG, Seibl R, Cochran DL. Bone apposition around two different sandblasted and acid-etched titanium implant surfaces: a histomorphometric study in canine mandibles. Clin Oral Implants Res. 2008;19(3):233-41.

23. Trisi P, Lazzara R, Rao W, Rebaudi A. Bone-implant contact and bone quality: evaluation of expected and actual bone contact on machined and osseotite implant surfaces. Int J Periodontics Restorative Dent. 2002;22(6):535-45.
24. Froum SJ, Simon H, Cho SC, Elian N, Rohrer MD, Tarnow DP. Histologic evaluation of bone-implant contact of immediately loaded transitional implants after 6 to 27 months. Int J Oral Maxillofac Implants. 2005;20(1):54-60.

25. Depprich R, Zipprich H, Ommerborn M, Naujoks C, Wiesmann HP, Kiattavorncharoen S, et al. Osseointegration of zirconia implants compared with titanium: an in vivo study. Head Face Med. 2008;4:30.

26. Novaes Ir AB, Souza SL, de Oliveira PT, Souza AM. Histomorphometric analysis of the bone-implant contact obtained with 4 different implant surface treatments placed side by side in the dog mandible. Int J Oral Maxillofac Implants. 2002;17(3):377-83.

27. Degidi M, Perrotti V, Piattelli A, lezzi G. Mineralized bone-implant contact and implant stability quotient in 16 human implants retrieved after early healing periods: a histologic and histomorphometric evaluation. Int J Oral Maxillofac Implants. 2010;25(1):45-8.

28. Deporter DA, Watson PA, Pilliar RM, Melcher AH, Winslow J, Howley TP, et al. A histological assessment of the initial healing response adjacent to porous-surfaced, titanium alloy dental implants in dogs. J Dent Res. 1986; 65(8):1064-70.

29. Deporter DA, Friedland B, Watson PA, Pilliar RM, Howley TP, Abdulla D, et al. A clinical and radiographic assessment of a porous-surfaced, titanium alloy dental implant system in dogs. J Dent Res. 1986;65(8):1071-7.

30. Albrektsson T, Branemark Pl, Hansson HA, Lindstrom J. Osseointegrated titanium implants. Requirements for ensuring a long-lasting, direct bone-toimplant anchorage in man. Acta Orthop Scand. 1981;52(2):155-70.

31. Carlsson L, Rostlund T, Albrektsson B, Albrektsson T. Removal torques for polished and rough titanium implants. Int J Oral Maxillofac Implants. 1988:3(1):21-4.

32. Wennerberg A, Albrektsson T, Andersson B, Krol J. A histomorphometric and removal torque study of screw-shaped titanium implants with three different surface topographies. Clin Oral Implants Res. 1995;6(1):24-30.

33. Buser D, Schenk RK, Steinemann S, Fiorellini JP, Fox CH, Stich $\mathrm{H}$. Influence of surface characteristics on bone integration of titanium implants. A histomorphometric study in miniature pigs. J Biomed Mater Res. 1991;25(7):889-902.

34. Gotfredsen K, Wennerberg A, Johansson C, Skovgaard LT, Hjorting-Hansen E. Anchorage of TiO2-blasted, HA-coated, and machined implants: an experimental study with rabbits. J Biomed Mater Res. 1995;29(10):1223-31.

35. Technical Data Sheet, 3M. Literature review. St. Paul, MN: 3M ESPE Dental Products, 2009.

36. Steigenga J, Al-Shammari K, Misch C, Nociti Jr FH, Wang HL. Effects of implant thread geometry on percentage of osseointegration and resistance to reverse torque in the tibia of rabbits. J Periodontol. 2004;75(9):1233-41.

37. Faeda RS, Tavares HS, Sartori R, Guastaldi AC, Marcantonio Jr E. Biological performance of chemical hydroxyapatite coating associated with implant surface modification by laser beam: biomechanical study in rabbit tibias. J Oral Maxillofac Surg. 2009;67(8):1706-15

38. He FM, Yang GL, Li YN, Wang XX, Zhao SF. Early bone response to sandblasted, dual acid-etched and $\mathrm{H} 2 \mathrm{O} 2 / \mathrm{HCl}$ treated titanium implants: an experimental study in the rabbit. Int J Oral Maxillofac Surg. 2009;38(6):677-81.

39. Rong M, Zhou L, Gou Z, Zhu A, Zhou D. The early osseointegration of the laser-treated and acid-etched dental implants surface: an experimental study in rabbits. J Mater Sci Mater Med. 2009:20(8):1721-8.

40. Marin C, Bonfante EA, Granato R, Suzuki M, Granjeiro JM, Coelho PG. The effect of alterations on resorbable blasting media processed implant surfaces on early bone healing: a study in rabbits. Implant Dent. 2011;20(2):167-77.

41. Yildiz A, Esen E, Kurkcu M, Damlar I, Daglioglu K, Akova T. Effect of zoledronic acid on osseointegration of titanium implants: an experimental study in an ovariectomized rabbit model. J Oral Maxillofac Surg. 2010;68(3):515-23.

42. Park YS, Yi KY, Lee IS, Han CH, Jung YC. The effects of ion beamassisted deposition of hydroxyapatite on the grit-blasted surface of endosseous implants in rabbit tibiae. Int J Oral Maxillofac Implants. 2005;20(1):31-8

43. Park JW, Kim HK, Kim YJ, An CH, Hanawa T. Enhanced osteoconductivity of micro-structured titanium implants (XVVE S CELLplus) by addition of surface calcium chemistry: a histomorphometric study in the rabbit femur. Clin Oral Implants Res. 2009;20(7):684-90. 
44. Yang GL, He FM, Yang XF, Wang XX, Zhao SF. Bone responses to titanium implants surface-roughened by sandblasted and double etched treatments in a rabbit model. Oral Surg Oral Med Oral Pathol Oral Radiol Endod. 2008; 106(4):516-24

45. Le Guehennec L, Goyenvalle E, Lopez-Heredia MA, Weiss P, Amouriq Y, Layrolle P. Histomorphometric analysis of the osseointegration of four different implant surfaces in the femoral epiphyses of rabbits. Clin Oral Implants Res. 2008;19(11):1103-10.

46. Green CJ, Knight J, Precious S, Simpkin S. Ketamine alone and combined with diazepam or xylazine in laboratory animals: a 10 year experience. Lab Anim. 1981;15(2):163-70.

47. Fan $Y$, Xiu K, Dong $X$, Zhang $M$. The influence of mechanical loading on osseointegration: an animal study. Sci China Ser C Life Sci. 2009; 52(6):579-86.

48. Zhao L, Xu Z, Yang Z, Wei X, Tang T, Zhao Z. Orthodontic mini-implant stability in different healing times before loading: a microscopic computerized tomographic and biomechanical analysis. Oral Surg Oral Med Oral Pathol Oral Radiol Endod. 2009;108(2):196-202.

49. Donath K, Breuner G. A method for the study of undecalcified bones and teeth with attached soft tissues. The Sage-Schliff (sawing and grinding) technique. J Oral Pathol. 1982;11(4):318-26.

50. Tsetsenekou E, Papadopoulos T, Kalyvas D, Papaioannou N, Tangl S, Watzek $\mathrm{G}$. The influence of alendronate on osseointegration of nanotreated dental implants in New Zealand rabbits. Clin Oral Implants Res. 2012;23(6):659-66.

51. Ahn MR, An KM, Choi JH, Sohn DS. Immediate loading with mini dental implants in the fully edentulous mandible. Implant Dent. 2004;13(4):367-72.

52. An YH, Woolf SK, Friedman RJ. Pre-clinical in vivo evaluation of orthopaedic bioabsorbable devices. Biomaterials. 2000;21(24):2635-52.

53. Klokkevold PR, Johnson P, Dadgostari S, Caputo A, Davies JE, Nishimura RD. Early endosseous integration enhanced by dual acid etching of titanium: a torque removal study in the rabbit. Clin Oral Implants Res. 2001;12(4):350-7.

54. Hayakawa $\mathrm{T}$, Yoshinari $\mathrm{M}$, Kiba $\mathrm{H}$, Yamamoto $\mathrm{H}$, Nemoto $\mathrm{K}$, Jansen JA. Trabecular bone response to surface roughened and calcium phosphate (Ca-P) coated titanium implants. Biomaterials. 2002;23(4):1025-31.

55. Sul YT, Byon ES, Jeong Y. Biomechanical measurements of calciumincorporated oxidized implants in rabbit bone: effect of calcium surface chemistry of a novel implant. Clin Implant Dent Relat Res. 2004;6(2):101-10.

56. Svanborg LM, Hoffman M, Andersson M, Currie F, Kjellin P, Wennerberg A. The effect of hydroxyapatite nanocrystals on early bone formation surrounding dental implants. Int J Oral Maxillofac Surg. 2011;40(3):308-15.

57. Breding K, Jimbo R, Hayashi M, Xue Y, Mustafa K, Andersson M. The effect of hydroxyapatite nanocrystals on osseointegration of titanium implants: an in vivo rabbit study. Int J Dentistry. 2014;2014:171305.

58. Shin D, Blanchard SB, Ito M, Chu TM. Peripheral quantitative computer tomographic, histomorphometric, and removal torque analyses of two different non-coated implants in a rabbit model. Clin Oral Implants Res. 2011;22(3):242-50

59. Roberts WE, Smith RK, Zilberman Y, Mozsary PG, Smith RS. Osseous adaptation to continuous loading of rigid endosseous implants. Am J Orthod. 1984;86(2):95-111.

60. Slaets E, Carmeliet G, Naert I, Duyck J. Early cellular responses in cortical bone healing around unloaded titanium implants: an animal study. J Periodontol. 2006;77(6):1015-24.

61. Marco F, Milena F, Gianluca G, Vittoria O. Peri-implant osteogenesis in health and osteoporosis. Micron. 2005;36(7-8):630-44.

62. Balkin BE, Steflik DE, Naval F. Mini-dental implant insertion with the auto-advance technique for ongoing applications. J Oral Implantol. 2001;27(1):32-7

63. Simon H, Caputo AA. Removal torque of immediately loaded transitional endosseous implants in human subjects. Int J Oral Maxillofac Implants. 2002; 17(6):839-45.

64. Krebs M, Schmenger K, Neumann K, Weigl P, Moser W, Nentwig GH. Long-term evaluation of ANKYLOS ${ }^{\circ}$ dental implants, part i: 20-year life table analysis of a longitudinal study of more than 12,500 implants. Clin Implant Dent Relat Res. 2015;17 Suppl 1:275-86.

65. Boyan BD, Hummert TW, Dean DD, Schwartz Z. Role of material surfaces in regulating bone and cartilage cell response. Biomaterials. 1996;17(2):137-46.
66. Schwartz Z, Lohmann CH, Oefinger J, Bonewald LF, Dean DD, Boyan BD Implant surface characteristics modulate differentiation behavior of cells in the osteoblastic lineage. Adv Dent Res. 1999;13:38-48.

67. Boyan BD, Lossdorfer S, Wang L, Zhao G, Lohmann $\mathrm{CH}$, Cochran DL, et al. Osteoblasts generate an osteogenic microenvironment when grown on surfaces with rough microtopographies. Eur Cell Mater. 2003;6:22-7.

68. Yan WQ, Nakamura T, Kobayashi M, Kim HM, Miyaji F, Kokubo T. Bonding of chemically treated titanium implants to bone. J Biomed Mater Res. 1997;37(2):267-75.

69. Marulanda J DJ, Alebrahim S, Romanos G, Feine J, Murshed M..Differential growth of MC3T3-E1 and C2C12 cells on 3M ${ }^{\mathrm{TM}}$ ESPE ${ }^{\mathrm{TM}} \mathrm{MDI}$ and Ankylos. J Dent Res 95 (Spec Iss. A) 2015. p. 4042.

\section{Submit your manuscript to a SpringerOpen ${ }^{\circ}$ journal and benefit from:}

- Convenient online submission

- Rigorous peer review

- Immediate publication on acceptance

- Open access: articles freely available online

- High visibility within the field

- Retaining the copyright to your article

Submit your next manuscript at $>$ springeropen.com 